\title{
On The Financial Characteristics Of Firms That Have Achieved The Highest Levels Of Accuracy In Earnings Predictability
}

\author{
Bruce C. Payne, (E-mail: bpayne@mail.barry.edu), Barry University \\ Adnan Daghestani, Barry University \\ Nancy Clark Rumore, University of Louisiana, Lafayette
}

\begin{abstract}
The value of a company is said to be a function of the future earnings or cash flows the company will produce discounted at a rate commensurate with risks associated with those cash flows. The subject of earnings predictability or the lack of reliable forecasts has been of interest to academic researchers and financial managers for years. Value Line publishes weekly, a ranking of the reliability of earnings predictions for every firm in their database. The higher the Value Line ranking for earnings predictability, the more likely they would recommend it as a safe investment. Earnings predictability is then, simply one of their important measures of potential value and safety. The purpose of this study is to provide a financial analysis of those firms described by Value Line as having the most reliable levels of earnings predictability in their database. Specifically, the analysis will test for significant differences in the financial profiles of those firms that achieved the highest Value Line ratings for earnings predictability, and companies selected at random from the same industries. A unique financial profile is established for the highest rated group, and it is suggested that the profile may be used to identify firms that because of their financial nature are capable of producing the most accurate sales forecasts, and earnings predictability. As in previous studies of this nature Multiple Discriminant Analysis is used.
\end{abstract}

\section{INTRODUCTION}

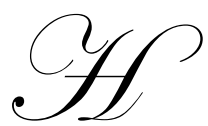

igh levels of accuracy in the prediction of earnings for companies have been considered an important factor in both safety and potential return on equity investments for many years. The reliability of earnings predictions has been the subject of many academic studies, and has always been of great interest to investors, investment counselors, financial managers, and academicians. Moreover, it is said that in periods of economic downturn the accuracy of earnings predictions may become of paramount importance. Graham, Campbell, and Rajgopal (2005) surveyed 401 financial executives, and conducted in-depth interviews with an additional 20, to determine the key factors that drive decisions related to performance measurement. They concluded that the majority of firms viewed earnings predictability as the key metric for an external audience, even more so than cash flows. They found also that the majority of managers would avoid initiating a positive net present value (NPV) project if it meant falling short of the current quarter's predicted earnings. They concluded that managers believe that anything that reduced the accuracy of the predictability of earnings in turn reduced stock prices because investors and analysts dislike uncertainty. An earlier finding stated that while the value of any firm may ultimately depend on its ability to generate earnings and positive cash flows, the predictability of those earnings are a primary concern to potential investors, particularly in a period or economic recession (Payne and Tyler 2002).

Affleck-Graves, Callahan, and Chipalkatti (2002) found consistency with previous theoretical work in the literature (e.g., Glosten and Harris 1988). They concluded, as did Glosten and Harris, that less predictable earnings signals aggravate the information asymmetries between privately informed investors and market-makers in the capital markets. To compensate for this informational disadvantage, the market-makers' increase in the bid-ask spread at the time an earnings announcement is expected. In the case of the company with the less predictable earnings the spread is 
more pronounced. Thus, they found that there exists an adverse selection component on the day of and the day prior to the earnings announcement date for firms with less predictable earnings. In contrast, they found no evidence of a significant change in any selection component of the bid-ask spread around quarterly earnings announcements of firms with highly predictable earnings.

The editors of Business Week Online (July 3, 2006) took the position that the accuracy of earnings predictability was an essential consideration in valuing firms. Accordingly, they surveyed three legitimate reporting services that have been very successful in predicting earnings to learn whatever they could about the methods used by those services. The three services were Morning Star, Standard and Poor's (S\&P), and Value Line.

Morning Star applied their "Wide Moat" proprietary system of ranking potential investments. (The firm classifies companies as having a wide moat, a narrow moat, or no moat at all.) Morningstar applied wide-moat and below-average business-risk qualifications to its 1,768-stock universe. To qualify for their five-star (strong buy) analyst recommendation a company had to have a good record of earnings predictability (Business Week Online, July 3, 2006).

Standard and Poor's rates 1,070 stocks from A+ to D on their earnings and stability over the past 10 years. Everything above A- is considered high quality; a grade below B+ places the stock in the low-quality category. However, an A+ alone doesn't merit a buy recommendation. S\&P's choices must also get a 5-star (strong buy) rating from an analyst, and their Stock Appreciation Ranking System (STARS) rates stocks according to an analyst's forecast of earnings predictability over the next year (Business Week Online, July 3, 2006).

Value Line unlike Morningstar and S\&P uses purely quantitative statistics to pick stocks. Earnings Predictability is one of their most important measures of safety, and potential return on investment. Predictability is based on the stability of year-to-year quarterly earnings comparisons. The earnings stability is calculated from the standard deviation of the percent changes in quarterly earnings over a 10 -year period with recent years weighed more heavily than earlier years. The very highest score, that given the companies with the most stable and predictable earnings, is 100, the lowest 5. (Value Line, 2007).

It would be a gross understatement to say earnings predictability particularly in markets such as those experienced in the United States from the period January 2000 to the economic recovery that continues at the time of this writing are of the utmost importance to investors. During that period there was an "economic bubble," a recession, a slow recovery, and finally a new prosperity with new records in the Dow Industrial index. All parties whether they were investors, sellers, financial counselors, or financial managers considered the characteristic of accurate earnings predictability to be of primary importance. However, the subject of earnings predictability, and the nature of firms that consistently have high ratings for the accuracy of earnings predictability have produced relatively little research..

The purpose of this study is to establish a financial profile of firms identified by Value Line as having the highest levels of earnings predictability in their database, and to determine whether these firms have financial profiles that are significantly different from firms selected at random. If such a profile is established, and it can be validated without bias, it is suggested that it may be used to predict firms that will maintain the highest levels of accuracy in earnings predictability in the future. This would have implications for financial managers, investors, investment counselors, and indeed, the entire market, and business community.

\section{METHODOLOGY}

The issues to be resolved are first, classification or prediction, and then evaluation of the accuracy of that classification. More specifically, can firms be assigned, on the basis of selected financial variables, to one of two groups: (1) firms chosen by Value Line for their highest ratings for earnings predictability (VLEP) ${ }^{1}$ or (2) firms chosen randomly (RCF), but from the same industries as the first group? Multiple discriminant analysis (MDA) provides a procedure for assigning firms to predetermined groupings based on variables or attributes whose values may depend on the group to which the firm actually belongs. 
If the purpose of the study were simply to establish a financial profile of each group of firms, simple ratios would be adequate. As early as 1968, in a seminal paper on the use of MDA in finance, Altman showed that sets of variables used in multivariate analysis were better descriptors of the firms, and had more predictive power than individual variables used in univariate tests.

The use of MDA in the social sciences for the purpose of classification is well known. MDA is appropriate when the dependent variable is nominally or ordinally measured and the predictive variables are intervally measured. In addition to its use in the Altman study to predict corporate bankruptcy, other early studies used MDA to, predict financially distressed property-liability insurance firms (Trieschmann and Pinches, 1973), growth (Payne, 1993), and the failure of small businesses (Edmister, 1982). This study also employs nominally measured dependent variables and intervally measured predictive variables. The nominally measured dependent variables are the group of VLEP firms and the group of RCF firms. The computer program used to perform the analysis is SPSS 11.5.0 Discriminant Analysis (SPSS Inc., 2002).

Since the objective of the analysis is to determine the discriminating capabilities of the entire set of variables without regard to the impact of individual variables, all variables were entered into the model simultaneously. This method is appropriate since the purpose of the study is not to identify the predictive power of any one variable, but instead the predictive power of the entire set of independent variables (Hair et al, 1992, 99).

\section{SELECTION OF SAMPLE AND INDEPENDENT VARIABLES}

All data used in the analysis were gathered from Value Line Ratings and Reports. Value Line ranks every firm in its database on a scale of 100 to 5 for accuracy in earnings predictability, where stocks with a ranking of 100 have the greatest accuracy and stocks ranked 5 have the least. The sample selected for this study consists of two groups of 100 firms. The first group was identified by Value Line as having the highest ratings in our sample. The second group is a group of 100 firms randomly selected from the Value Line database, but from the same industries as the first group.

In periods of economic decline, recession, and recovery all industries will not experience the same effects whether they are adverse or beneficial. It follows that for an unbiased study the effects of industry must be held constant. This was accomplished by matching the companies in the VLEP group with companies from the same industry in the RCF group. For example, from the recreation industry, Royal Caribbean Cruises is in the VLEP group, and Six Flags Inc. is in the RCF group. From the toiletries/cosmetics industry, Gilette is in the VLEP group, and Revlon is in the RCF group. From the computer industry, Dell is in the VLEP group and Apple Inc. RCF group. Black and Decker is in the VLEP group from the home appliances industry, and Whirlpool is in the RCF group. In this manner each company identified by Value Line as having high ratings for earnings predictability was matched with a randomly chosen company, from the same industry. Thus, the matching method of randomly choosing, and matching companies from the same industries eliminates any bias due to differences in industry listings.

Previous studies using this and other statistical methods have chosen explanatory variables by various methods and logical arguments.

In this study the group of explanatory variables chosen for analysis includes a measure of the size of the firm, two measures of risk, both of which would contribute to volatility in the movement of stock prices, two measures of what may be described as the lack of risk, two measures of how investors at the margin (those willing and able to buy) perceive the potential value of the companies, and finally, a measure of institutional investor interest in the companies. An evaluation of these measures is needed to accomplish the purpose of this study.

It is possible that some investors perceive that earnings predictability is in some way associated with the size of the firm. That is, there may be a significant number of investors at the margin believe that investments in larger firms may be more attractive than those in the smaller firms. There has been no published empirical evidence of this. The relationship between size and earnings predictability, if any, is simply not known. Thus, there is no aprori expectation. Therefore, it will be informative to include a measure of size. The measure of size is the $\log$ of sales. 
Sharpe's beta coefficients contain the effects of both operating and financial risk. It is felt that the VLEP firms may have less of both types of risk than the RCF. This may not be the case however, and separate measures of financial and operating risk, (or leverage) will identify any differences. The separation is accomplished by using Hamada's (1969) equation to "unlever" the published betas. The unlevered beta is used as a measure of operating risk, and the debt to total capital ratio as the measure of financial risk, or financial leverage.

The Value Line rating for financial strength is used here as a measure of the absence of risk. The concept and measurement of a company's financial strength is an important topic for investors and financial managers alike. Financial managers usually investigate a company's financial strength when trying to decide whether to use that company as a supplier, customer, or subcontractor. Both Value Line and Standard and Poors report company's financial strength in nine categories. They range in Value Line from "A++" to "C," and in Standard and Poors from "AAA to CC." The highest rating is given to companies with exceptional financial strength and the lowest rating is awarded to companies that are close to bankruptcy. Very few companies qualify for the A++ rating in Value Line. For example, there are only 40 companies in their database of 1700 companies that are designated as A++. Among those are Coca Cola, General Electric, and Home Depot (O'Shaughnessy, 1998). It is expected that companies that have been rated high for earnings predictability may have more borrowing capacity, and greater financial strength than the RCF.

The price level stability of common stocks may be considered another measure of the lack of risk, or safety in an investment. Safety of investment is always of interest to investors, investment counselors, financial managers, and academicians, and in periods of economic downturns it may become of paramount importance. The measure of price level stability used in this study is the Value Line Stock Price Stability Rating. It is defined by Value Line as a relative ranking of the standard deviation of weekly percent changes in the price of a stock over the past five years. The ranks range from 100 for the most stable to 5 for the least stable. (Value Line 2007)

The ratio of market value to book value is used here as a measure of how the market perceives the value of the firm. This ratio has been shown to be of great significance in the identification of takeover targets (Payne and Heron 1985). There is no published evidence on how this measure of value is related to earnings predictability. Consequently, there are no aprori expectations, except that logic would seem to lead one to the belief that the higher the level of earnings predictability, the greater would be the numerator (market price) and thus, the greater would be the value of the ratio.

The ratio of market price to earnings $(\mathrm{P} / \mathrm{E})$ has been used for years as a rough measure of how the market values a firm. Indeed, the P/E multiple, and dividend yield are the only ratios reported every day on the financial pages of newspapers, and it has been argued that in efficient markets the multiple reflects the intrinsic value of the stocks, (Scripto, 1998, Payne and Tyler 2002). More recently, the price earnings growth ratio (PEG) has grown in popularity. The price earnings growth multiple adjusts the P/E ratio for potential growth, and it is suggested that the price earnings multiple (P/E) used without the adjustment for growth has a high potential for undervaluing a company. Damodaran, (2002) writes that the PEG ratio is a better measure of a company's potential future value, and was developed to address the shortcomings of the P/E multiple. He further writes that many analysts have abandoned the $\mathrm{P} / \mathrm{E}$ ratio, not because of any perceived shortcomings, but simply because they desire more information about a stock's potential. Thus, the use of the PEG ratio is used here as a measure of a company's potential long term value to investors, and it is expected that this ratio will be greater for the VLEP group because, as was the case in the previous ratio, the numerator should reflect the high ratings for earnings predictability.

The activity of institutional investors has long been a favored topic in financial literature. It seems reasonable that institutional investors would be attracted to firms that rank high in earnings predictability, but there is little empirical evidence of this. However, logic dictates that there will be a positive relationship between institutional ownership and high levels of earnings predictability. Regardless of the relationship, institutional investors cannot be ignored in any study of this nature. The Conference Board (2007) reported that the daily trading of such investors now varies between 50 and 70 percent of all daily trading on the New York Stock Exchange. They further reported that institutional investors are gaining even greater control of United States equity markets. Their report stated that in 2000, these institutions controlled 51.4 percent of all outstanding equities in the U.S., but in 2005 that amount increased to 61.2 percent. In the year 2000, they controlled 61.4 percent of the equity of the largest 1000 corporations. 
By 2005, they controlled 67.9 percent of those corporations. Logic seems to suggest that since institutional investors include such entities as college endowments, and other trust funds that are interested in safety they would be attracted to firms with high levels of earnings predictability. However, a search of the literature found no studies that address this relationship directly. Thus, a variable is included that reflects institutional investor interest.

A basic tenet of this study is that investors at the margin evaluate the degree of risk in an investment and compare it to the investment's potential rate of return. In modern finance textbooks this is a fundamental principle referred to as the "risk-return tradeoff." (Van Horne, 2001) Investors at the margin "trade off" proxies for risk and return in buying and selling securities to establish demand and thus, price or market value. Earnings predictability stability is simply one side of that tradeoff, but when investors become more risk adverse, as in a recent period of recession and slow recovery, they have to realize a greater potential return to assume marginal risks.

In sum, there are eight explanatory variables in the multiple discriminant model. They are as follows:

X1 - The Logarithm of Sales - (Size)

X2 - Operating Leverage - (Unlevered Beta)

X3 - Long Term Debt to Total Capital

X4 - Value Line's Rating for Financial Strength

X5 - Value Line's Rating for Price Stability

X6 - The Ratio of Market Value to Book Value

X7 - The Price Earnings Growth Ratio

X8 - Institutional Investor Buying and Selling

The explanatory variable profile contains basic measures of common financial variables. They were chosen, as in any experimental design, because of their consistency with theory, adequacy in measurement, the extent to which they have been used in previous studies, and their availability from a reputable source.

\section{TESTS AND RESULTS}

The discriminant function used has the form:

$Z_{\mathrm{j}}=\mathrm{V}_{1} \mathrm{X}_{\mathrm{1j}}+\mathrm{V}_{2} \mathrm{X}_{2 \mathrm{j}}+\ldots .+\mathrm{V}_{\mathrm{n}} \mathrm{X}_{\mathrm{nj}}$

where:

$X_{\mathrm{ij}}$ is the firm's value for the ith independent variable.

$V_{i}$ is the discriminant coefficient for the firm's jith variable.

$\mathrm{Z}_{\mathrm{j}}$ is the $\mathrm{jth}$ individual's discriminant score.

The function derived from the data in this study and substituted in equation 1 is:

$\mathrm{Z}_{\mathrm{j}}=1.386+.077 \mathrm{X}_{1}+.924 \mathrm{X}_{2}+.183 \mathrm{X}_{3}-.632 \mathrm{X}_{4}-.006 \mathrm{X}_{5}+.024 \mathrm{X}_{6}+.019 \mathrm{X}_{7}-.002 \mathrm{X}_{8}$

Classification of firms is relatively simple. The values of the eight variables for each firm are substituted into equation (2). Thus, each firm in both groups receives a $Z$ score. If a firm's $Z$ score is less than a critical value, the firm is classified in group one (VLEP). Conversely, a $\mathrm{Z}$ score more than the critical value will place the firm in group two (RCF). Since the two groups are heterogeneous, the expectation is that VLEP firms will fall into one group and the RCF firms will fall into the other. questions:

Interpretation of the results of discriminant analysis is usually accomplished by addressing four basic 
1. Is there a significant difference between the mean vectors of explanatory variables for the two groups of firms?

2. How well did the discriminant function perform?

3. How well did the independent variables perform?

4. Will this function discriminate as well on any random sample of firms as it did on the original sample?

To answer the first question, SPSS provides a Wilk's Lamda - Chi Square transformation (Cooper and Schindler, 2001, 581). The calculated value of Chi-Square is 77.43. That exceeds the critical value of Chi-Square of 15.51 at the five percent level of significance, with 8 degrees of freedom. The null hypothesis that there is no significant difference between the financial profiles of the two groups is therefore rejected, and the first conclusion drawn from the analysis is that the two groups have significantly different financial characteristics. This result was of course, expected since one group of firms possessed Value Line's highest rankings for earnings predictability and the other group was chosen randomly.

The discriminant function thus has the power to separate the two groups. However, this does not mean that it will in fact separate them. The ultimate value of a discriminant model depends on the results obtained. That is what percentage of firms as classified correctly and is that percentage significant?

To answer the second question a test of proportions is needed. Of the 100 firms in the VLEP group, 77 were classified correctly. Of the 100 firms in the RCF group, 79 were classified correctly. That is, 156 firms or 78 percent were classified correctly. The results are shown in Table 1.

Table 1

\section{Classification Results}

Predicted Results VLEP- RCF Classification

$\begin{array}{lcr}\text { Actual Results } & \text { VLEP } & \text { RCF } \\ \text { VLEP } & 77 & 23 \\ \text { RCF } & 21 & 79\end{array}$

Of course 78 percent is significant, but formal research requires the proof of a statistical test. To test whether or not a 78 percent correct classification rate is statistically significant, the Press's Q test is appropriate (Hair et al, 1992, 106). Press's Q is a Chi-square random variable:

Press's $\mathrm{Q}=[\mathrm{N}-(\mathrm{n} \quad \mathrm{x} \quad \mathrm{k})]^{2} / \mathrm{N}(\mathrm{k}-1)$

where:

$\mathrm{N}=$ Total sample size

$\mathrm{n}=$ Number of cases correctly classified

$\mathrm{k}=$ Number of groups

In this case:

Press's $Q=[200-(156 \times 2)]^{2} / 200(2-1)=62.72>\chi^{2}{ }_{.05} 3.84$ with one d. f.

The null hypothesis that the percentage classified correctly is not significantly different from what would be classified correctly by chance is rejected. The evidence suggests that the discriminant function performed very well in separating the two groups. Again, given the disparity of the two groups, it is not surprising that the function classified seventy eight percent correct. 
The arithmetic signs of the adjusted coefficients in Table 2 are important to answer question number three. A negative sign indicates that the greater a firm's value for the variable, the more likely it will be in group one, the VLEP group. On the other hand, a positive sign for an adjusted coefficient signifies that the greater a firm's value for that variable, the more likely it will be classified in group two, the RCF group. Thus, according to Table 2, the greater the following variables: the Value Line rating for financial strength, the Value Line rating for financial stability, the size of the firm, and the firm's attractiveness to institutional investors, the more likely the firm would achieve a high level of accuracy in earnings predictability. Conversely, the greater both the operating and financial risk, the greater the ratio of market value to book value, and the greater the price-earnings-growth ratio, the more likely the firm would be randomly chosen for this study.

The relative contribution of each variable to the total discriminating power of the function may be obtained by standardizing (pooled within group variances) the canonical coefficients of the discriminant function. These coefficients are given in the output of the SPSS 11.5.0 program. The standardized canonical coefficients are shown in Table 2.

Table 2

\section{Relative Contribution Of The Variables}

\begin{tabular}{|c|c|c|c|}
\hline & Adjusted Variables & Coefficient & Rank \\
\hline $\mathrm{X} 1-$ & The Logarithm of Sales - (Size) & 0.115 & 4 \\
\hline $\mathrm{X} 2$ - & Operating Leverage - (Unlevered Beta) & 0.345 & 3 \\
\hline X3 - & Long Term Debt to Total Capital & 0.045 & 8 \\
\hline X4 - & Value Line's Rating for Financial Strength & -0.851 & 1 \\
\hline X5 - & Value Line's Rating for Price Stability & -0.143 & 2 \\
\hline X6 - & The Ratio of Market Value to Book Value & 0.311 & 6 \\
\hline$X 7-$ & The Price Earnings Growth Ratio & 0.237 & 5 \\
\hline $\mathrm{X} 8$ - & Institutional Investor Buying and Selling & -0.052 & 7 \\
\hline
\end{tabular}

Table 2 reveals that the measure of financial strength made the greatest contribution to the overall discriminating function. It is followed respectively by the Value Line measure of financial stability, the level of operating risk, the size of the firm, the price-earnings-growth ratio, the ratio of market value to book value, institutional investor buying, and finally the level of financial leverage. Some multicollinearity may exist between the variables, because strength, and stability could be reflected in the numerator of the price-earnings-growth ratio, institutional investor purchases, and both types of risk could also be reflected in the numerator of that ratio. Hair, et al (1992) wrote that this consideration becomes critical in stepwise analysis and may be the factor determining whether a variable should be entered into a model. However, when all variables are entered into the model simultaneously, the discriminatory power of the model is a function of the variables evaluated as a set and multicollinearity becomes less important.

\section{VALIDATION OF THE MODEL}

Before any general conclusions can be drawn, a determination must be made on whether the model will yield valid results for any group of randomly drawn firms. The procedure used here for validation is referred to as the Lachenbruch or, more informally, the "jackknife" method. In this method, the discriminant function is fitted to repeatedly drawn samples of the original sample. The procedure estimates $(\mathrm{k}-1)$ samples, and eliminates one case at a time from the original sample of " $k$ " cases (Hair et al, 1992, 98). The expectation is that the proportion of firms classified correctly by the jackknife method would be less than that in the original sample due to the systematic bias associated with sampling errors. The major issue is whether the proportion classified correctly by the validation test differs significantly from the 78 percent classified correctly in the original test. That is, is the difference in the two proportions classified correctly by the two tests due to bias, and if so is that bias significant? The jackknife validation resulted in the correct classification of 78 percent of the firms. Since there are only two samples for analysis the binomial test is appropriate:

$154-200(.78) /[200(.78)(.22)]^{1 / 2}=-.34$ is less than $\mathrm{t}_{05} 1.645$. 
Thus, the null hypothesis that there is no significant difference between the proportion of firms classified correctly in the original test and the proportion classified correctly in the validation test cannot be rejected. Therefore, it can be concluded that while there may be some bias in the original analysis, it is not significant. The procedure will classify new firms as well as it did in the original analysis.

In addition to the validation procedure, researchers usually address the question of the equality of matrices. One of the assumptions in using MDA is that the variance-covariance matrices of the two groups are equal. The SPSS program tests for equality of matrices by means of Box's M statistic. In this study Box's M transformed to the more familiar F statistic of 3.83 resulted in a zero level of significance. Thus, the null hypothesis that the two matrices are equal cannot be rejected, and the midpoint value between the two group means can be defined as the critical $\mathrm{Z}$ value.

\section{SUMMARY AND CONCLUSIONS}

The purpose of this study was to establish a financial profile of firms identified by Value Line as having the highest levels of earnings predictability in their database, and to determine whether these firms have financial profiles that are significantly different from firms selected at random. The results of the statistical analysis indicated first, that there was a significant difference between financial variables that determine value, between the group of firms with high rankings for earnings predictability, and firms chosen randomly, but from the same industries as the first group. The fact that the discriminant function separated two heterogeneous groups, and classified a significant proportion correctly is no surprise. In fact, the two groups of firms are so diverse in the matter of earnings predictability that it would certainly have been a surprise if the discriminant function had not been so efficient. It was suggested that each group would have a unique financial profile. Table 2 summarizes the findings. According to Table 2, the greater the following variables: the Value Line rating for financial strength, the Value Line rating for financial stability, the size of the firm, and the firm's attractiveness to institutional investors, the more likely the firm would achieve a high level of accuracy in earnings predictability. Conversely, the greater both the operating and financial risk, the greater the ratio of market value to book value, and the greater the price-earnings-growth ratio, the more likely the firm would be randomly chosen for this study.

Five of these results may have been expected, two were surprises, and one simply had no apriori expectations. Explanations of why the variables are associated with one group or the other are beyond the scope of this study. However, a few comments on the findings may be in order.

The variables ranked one, two, and three in their contributions to the discriminating function were financial strength, stock price stability, and the measure for operating risk. Financial strength and stock price stability were characteristics of firms with high levels of earnings predictability, while operating risk was associated with firms chosen randomly for this study. These results were expected. Financial strength contributes to the ability of firms to undertake profitable projects, and stock price stability is a measure of the lack of variation in stock prices. To the extent that those prices are a partial function of earnings, these results had to be expected and the conclusions are consistent with previous studies, and popular textbooks. Sharpe's unlevered beta was used as a measure of operating risk. Operating risk is a function of operating fixed costs. In contrast to financial fixed costs, there is not much a financial manager can do about the level of operating fixed costs in a company. However, operating fixed costs (operating leverage) contribute to variation in earnings, and thus, cannot be a characteristic of firms with high ratings for earnings predictability. For much the same reason the measure of financial risk (financial leverage) was not a characteristic of firms with high ratings for earnings predictability. The greater the levels of financial risk, the greater will be the variation in earnings. The most popular measure of undiversifiable risk is Sharpe's beta, and published betas contain the effects of both operating and financial leverage.

It was simply not known whether the size of the firm was in any associated with earnings predictability. Thus, there was not apriori expectation. Table 2 reveals that the greater the size of the firm, the more likely the firm would have high ratings for earnings predictability. There is nothing in the literature that expressly addresses this matter. A simple suggestion, that should not be construed as a concrete reason, is that larger firms have more people and more resources to predict earnings. 
It seems reasonable that institutional investors would be attracted to firms that rank high in earnings predictability, but there was little empirical evidence of this. However, logic dictates that there should be a positive relationship between institutional ownership and high levels of earnings predictability. Institutional investors include such entities as college endowments, and other trust funds that are interested in the safety of their investments. Thus, they should be attracted to firms with high levels of earnings predictability, and this result was also expected.

The study resulted in two mild surprises. The price-earnings-growth ratio, and the market value to book value ratio both reflect value. In fact, the numerators in both ratios measure value. It was expected that since a high level of earnings predictability is a desirable characteristic of a firm, and one that measures the lack of risk, both of the said ratios should have been associated with the group of firms with high ratings for earnings predictability. No explanation for these phenomena can be offered here, and the two results may defy logic. However, the two latter conclusions are rich in content for needed further research.

This study has resulted in a contribution toward the construction of a theory that describes the financial characteristics of firms that have attained high levels of earnings predictability It is further suggested that since the model was validated without bias, it can be used to predict firms that will attain high ratings for earnings predictability in the future. In order to make a more complete contribution to the theory, the aforementioned further research is needed. The construction of a complete theory would aid managers, investors, academicians, and investment counselors by providing greater of knowledge on which to base investment decisions.

\section{ENDNOTES}

Value Line Earnings Predictability. This is a measurement of the reliability of an earnings forecast. Predictability is based on the stability of year-to-year quarterly earnings comparisons. The earnings stability is calculated from the standard deviation of the percent changes in quarterly earnings over a 10-year period with recent years being weighted more heavily than earlier years. The very highest score, that given the companies with the most stable and predictable earnings, is 100, the lowest 5 (Value Line, 2007).

As a group, each of the Value Line ratings have historically outperformed the next lowest rated group (the one hundreds have outperformed the nineties, which outperformed the eighties, etc.). Value Line results have outperformed the DOW by 15 to 1 over the last 35-years. (Investor Home, 1999). The impressive performance of the rating system led many to refer to it as part of the "Value Line Anomaly," or the "Value Line Enigma."

- $\quad$ http://www.valueline.com/sup glosss.html

- $\quad$ http://www.investorhome.com/anomvl.htm

\section{REFERENCES}

1. Affleck-Graves, John., Carolyn M. Callahan, and Niranjan Chipalkatti. Earnings Predictability, Information Asymmetry, and Market Liquidity. Journal of Accounting Research, Volume 40, Number 3, June 2002, 561 583.

2. Altman, Edward I. Financial Ratios, Discriminant Analysis and the Prediction of Corporate Bankruptcy. Journal of Finance, 23, no.4, September 1968, 589-609.

3. Cooper, Donald R., and Pamela S. Shindler. Business Research Methods Boston: McGraw-Hill Irwin, 2001.

4. Damodaran, Aswath. Investment Valuation: Tools and Techniques for Determining the Value of any Asset: John Wiley and Sons, New York, 2002.

5. Edmister, Robert O. An Empirical Test of Financial Ratio Analysis for Small Business Failure Prediction Journal of Financial and Quantitative Analysis 7, no.2, March 1982, 1477-1492.

6. Glosten, Lawrence R., and Lawrence E. Harris. Estimating the components of the bid/ask spread, Journal of Financial Economics. XXI 1 May 1988, 123-142.

7. Graham, John R. Campbell Harvey, and Shiva Rajgopal. The Economic Implications of Corporate Financial Reporting Journal of Accounting and Economics, vol. 40, issue 1-3, 2005, 3-73. 
8. Hair, Joseph F., Ralph E. Anderson, Ronald L. Tatham, and William C. Black. Multivariate Data Analysis, New York: Macmillian Publishing Firm, 1992.

9. Hamada, Robert S. The Effect of Firm's Capital Structure on the Systematic Risk of Common Stocks, Journal of Finance, May 1972, pp. 435-452.

10. Hamada, Robert S. Portfolio Analysis, Market Equilibrium, and Corporation Finance, Journal of Finance 24 (March 1969), 19 - 30.

11. How To Fight The Undertow, Business Week Online, July 3, 2006. http://www.businessweek. com/magazine/content/06_27/b3991095.htm

12. O’ Shaughnessy, James. How to Retire Rich, New York: Broadway Publishing, 1998.

13. Payne, Bruce C. A Multiple Discriminant Investigation Into the Financial Characteristics of High Growth Firms. Advances In Quantitative Analysis of Finance and Accounting. 2: 1993,19-33.

14. Payne, Bruce C. and Michael J. Tyler, Differences in the Financial Variables That Determine the Value for Firms with the Highest and Lowest Price Earnings Multiples. Journal of Accounting and Finance Research, X 1(Spring 2002): 61-69.

15. Payne, Bruce C., and Jane M. Heron An Empirical Investigation Into the Risk-Return Characteristics of Takeover Targets. Journal of Economics and Finance, (September 1985): 103-110.

16. Scripto, Philip. How to Get the PE Ratio You Want. Investor Relations Business(April, 1998): 1-8

17. The Conference Board, U.S. Institutional Investors Continue to Boost Ownership of U.S. Corporations. January 22, 2007. http://www.conference-board.org/UTILITIES/ pressDetail.cfm?press_ID=3046

18. The Value Line Anomaly and Investor Shortfall, Investor Home 1999. http:// www. investorhome.com/anomvl.htm

19. Treschmann, James S., and George E. Pinches. A Multivariate Model for Predicting Financially Distressed Property-Liability Insurers. Journal of Risk and Insurance, 40, no. 3: September 1973, 27-333.

20. Value Line, 2006. http://www.valueline.com/sup_glosss.html

21. Value Line, 2007. The Value Line Investment Survey Program 20, Educational series: Financial Strength, Stock's Price Stability, Price Growth Persistence, and Earnings Predictability, plus footnotes. http://www.valueline.com/video/edu/eduvlis20.aspx

22. Van Horne, James C. Financial Management and Policy, New York: Prentice-Hall Publishing, 2001.

\section{NOTES}

